\title{
Human Error Identification based on EEG Analysis for the Introduction of Digital Devices in Nuclear Power Plants
}

\author{
Yeon Ju Oh, Yong Hee Lee \\ I\&C and Human Factors Division, Korea Atomic Energy Research Institute (KAERI), Daejeon, 305-353
}

\begin{abstract}
Objective: This paper describes an analysis of electroencephalography(EEG) signals to identify human errors during using digital devices in nuclear power plants(NPPs). Background: The application of an advanced main control room(MCR) has accompanied with lots of changes in different forms and features by virtue of new digital technologies. The characteristics of these digital technologies and devices provide several opportunities for the use of interface management. It can integrate into a compact single workstation in an advanced MCR, allowing workers to operate the plant with minimum physical burden under any operating condition. However these devices may introduce new types of human errors, and thus we need a means to assess and prevent such errors especially those related to digital devices. Method/Conclusion: The EEG data are relatively objective, and thus we introduce several measures to EEG analysis for obtaining the feasibility of human error identification. Application: This study may support to ensure the safety when applying digital devices in NPPs.
\end{abstract}

Keywords: EEG, Human Error, Digital Devices, NPPs

\section{Introduction}

\subsection{Human errors and digital devices in NPPs}

원자력발전소(이하 원전) 주제어실에서는 대형정보표시장 치와 터치 스크린 등 다양한 최신 디지털 기기를 응용하려고 한다. APR 1400 과 같은 첨단 원전의 주제어실은 디지털 기 반으로 설계되어 기존 제어실과 같이 병렬식으로 정보를 제 공하는 것이 아니라, 핵심 정보를 제외한 대부분의 정보가 표시 및 제어기를 통해 계층적으로 구조화되어 있다. 따라서, 운전원은 신체적인 이동 없이 그 자리에서 작업할 수 있다 (Figure 1).

밀착 및 대형 체계 특성을 가진 원전의 특성상 사소한 기 기 결함에 의한 인적오류가 치명적인 결과를 야기할 수 있으 나 디지털 기기 도입에 따른 인적오류 평가의 중요성이 나타
남에도 불구하고 평가가 어렵다. 인적오류 영향 및 결과의 파급범위는 예측 불가능한 손실을 초래할 수 있고 발생 확률 이 매우 낮아 통계적 접근 또한 곤란하다. 매우 빠른 생명 주기 사이클 때문에 발전소 도입이 지연되고 있는데 이는 안전성 확보가 우선시 되어야 하기 때문이다(Lee, 2011).

디지털 기기 도입으로 새로워진 작업환경에서 예외적인 인적오류 경험 사례가 나타나면서 인적오류 발생 가능성에 대한 기존 접근 방법론으로는 제한점이 있다. 인간-기계환경의 상호작용 하에서 디지털 기기는 기존의 하드웨어 기 능 중심의 위험성 분석만으로는 전체 체계의 신뢰도 확보 가 어렵다. 이는 디지털 기기의 인적오류에 대한 사후적, 시행착오적 접근이 아닌 발생 메커니즘에 대한 실험적, 분석 적 연구로 사전적, 예방적 접근이 필요하다(Lee, KAERI/ TR-4575, 2011).

Corresponding Author: Yong Hee Lee. I\&C and Human Factors Division, Korea Atomic Energy Research Institute (KAERI), Daejeon, 305-353. Phone: +82-42-868-2941, E-mail: yhlee@kaeri.re.kr Copyright@2013 by Ergonomics Society of Korea(pISSN:1229-1684 eISSN:2093-8462). All right reserved.

(c) This is an open-access article distributed under the terms of the Creative Commons Attribution Non-Commercial License(http://creativecommons.org/licenses/by-nc/3.0/), which permits unrestricted non-commercial use, distribution, and reproduction in any medium, provided the original work is properly cited. http://www.esk.or.kr 


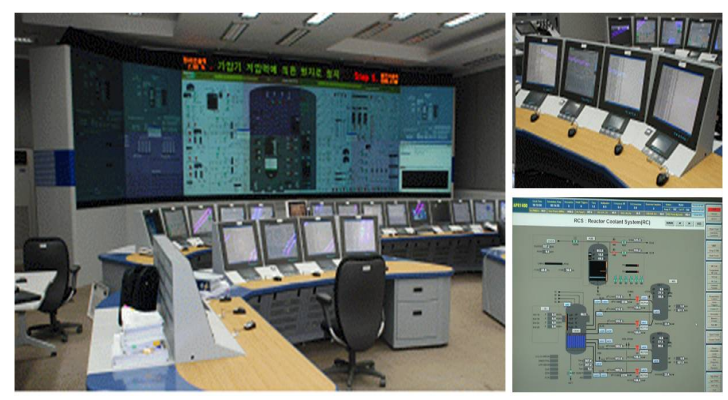

Figure 1. Advanced MCR in NPP

\subsection{A method for human error hazard identification in digital devices}

원자력 산업에서는 시스템의 신뢰도 분석과 함께 인적오 류 분석 방법의 일환으로 인간 신뢰도 분석과 인간공학적 확인 검증을 통해 인적오류를 예방하는 방법이 있다. 이는 사고 사례를 경험으로 분석 가능한 방법으로써 발생빈도가 매우 적은 원자력 산업에서는 유사 사고로도 사례를 도출하 기 어렵다. 또한 선형적인 사고원인 관계 설정으로 사고 해 석을 단순화시키고 다양한 분석 정보가 불충분하여 분석관 점에도 한계를 가져온다.

Oh(2011)의 연구에서는 인적오류 연구의 접근 방법을 이용희의 선행연구를 기반으로 quantitative, qualitative, managerial approach로 구분하였다. 정량적인 접근 방법은 물리적이고 반복적인 일상 작업에 대해서는 효과적으로 적 용할 수 있지만 인간의 정보처리 과정을 포함하는 작업에서 는 비효율적이다. 관리적 접근 방법은 인적오류의 종합적 대 응 관리를 위한 것으로 IAEA나 OPIS에 포함된 DB 및 관 리 체계를 말한다. 반면, 정성적인 접근 방법에서는 인적오 류 원인과 결과를 규명하는 기존 방법과는 달리 인간의 정 보처리 과정에 기반한 인지적 상태를 파악한다. 그러나 제약 조건이 많고 실험적 평가는 실험환경에 의한 통제불능 수준 의 노이즈가 발생될 우려가 있다(Table 1).

디지털 기기의 사용에 따른 사회, 경제적으로 많은 어려 움이 따르고 위험을 예측하기 어렵지만 현재도 원전에 다양 한 디지털 기기들이 도입되고 있으며, 스마트 모바일 기기 또한 적용을 위하여 많은 노력이 이루어지고 있다. 한 예로 $\mathrm{HALDEN}$ 에서는 MCR 운전원과 현장 운전원 간의 의사소 통 및 정보전달을 스마트 모바일을 통하여 text로 전달하거 나, 기기의 위치를 AR (augmented reality) 또는 VR (virtual reality)을 이용하여 알려주는 등 다양한 방향으로 노력하고 있다.

현실적으로 EMI(electromagnetic interference)로 인하 여 무선 기기의 도입이 어려운 실정이나, 이를 해결하고 난
Table 1. A method of human error study

\begin{tabular}{c|l}
\hline Method & \multicolumn{1}{c}{ Contents } \\
\hline $\begin{array}{c}\text { Quantitative } \\
\text { approach }\end{array}$ & $\begin{array}{l}\text { - Circuit controller and simulation } \\
\text { - Probability approach(THERP etc.) } \\
\text { - Numerical model(Event tree, HCR etc.) }\end{array}$ \\
\hline & - Error study(Cognitive error, Group error, etc.) \\
& - Classification analysis(Cause, Result, etc.) \\
$\begin{array}{c}\text { Qualitative } \\
\text { approach }\end{array}$ & $\begin{array}{l}\text { - Risk analysis(HAZOP, PHECA etc.) } \\
\text { - Analysis based on model } \\
\text { (Cognitive process, Rasmussen etc.) }\end{array}$ \\
& - Experiment approach(EEG, ECG, GSR, etc.) \\
\hline $\begin{array}{c}\text { Managerial } \\
\text { approach }\end{array}$ & $\begin{array}{l}\text { - HPES, HFACS etc. } \\
\text { - The management system and database } \\
\text { (in IAEA-IRS/LER, OPIS-NEED) }\end{array}$ \\
\hline
\end{tabular}

후 무선 기기 사용이 가능해진다면 주제어실 뿐만 아니라 현장에서의 직무가 많은 부분 변경될 것으로 예상된다. 따 라서 디지털 기기 사용에 앞서 사전에 디지털 기기에 기반 한 직무 수행에 따른 오류를 예측하는 것이 필요하다(Yun, 2011). 본 연구에서는 인적오류 분석을 위한 접근 방법을 몇 가지 사전 연구에 기반하여 수행하였는데, 본 연구의 맥 락을 위해 선행연구의 개요를 소개한다.

Jang (2003) 연구에서는 인적오류의 사전적 분석을 통해 기기와 기기와의 상호작용을 분류하여 Error Segment와 Interaction Segment(IS)를 정의하였다(Figure 2). 기기와 사용자의 상호작용을 표현하는 기본 단위로 기능, 영향요소, 변화된 기능, 효과 등이 있으며 단위 상호작용이 직무상 인 적오류의 일부가 되는 경우(부정적인 영향을 야기하는 가능 성을 가진 경우)로 오류 절편(ES)을 정의했다.

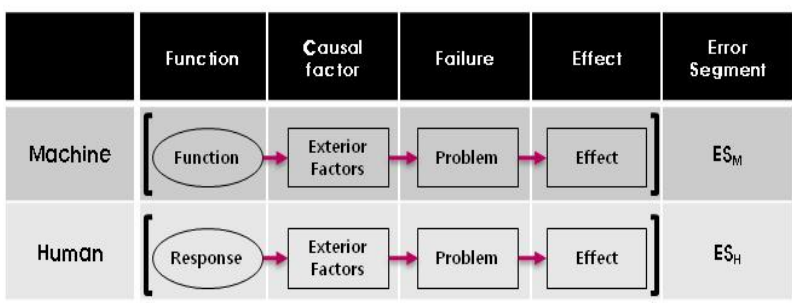

Figure 2. Error segment(ES)

이 선행연구를 기반으로 Yun(2010) 연구에서는 기기의 조작 상태와 방법에 따른 인간공학적 설계 요건검토를 평가 하였다. 또한 직무 기반 디지털 기기의 디자인, 작업환경 등 을 고려하여 평가 척도를 선정하였다(Figure 3). 또한, Lee 
(2011)는 기기의 고유 특성과 인간의 조작 행위를 하나의 상호작용 단위로 간주한 것을 상호작용절편(IS)으로 정의하 여 인적오류 위험성을 분석한 바 있다. 직무상 인적오류로 발현되는 상호작용절편 중 디지털 기기의 사용 관련 오류로 귀결되는 것을 오류절편(ES)로 다시 분류하였다. 디지털 기 기의 인적오류 위험성을 검출하기 위한 기법의 절차는 기기 의 사용자 조작 부위 및 기기를 이용한 예상 직무의 세부요 소를 도출한 후에, 인간공학적 평가 척도들로써 인적오류의 발생 가능성을 판단하는 과정을 제시하였다.

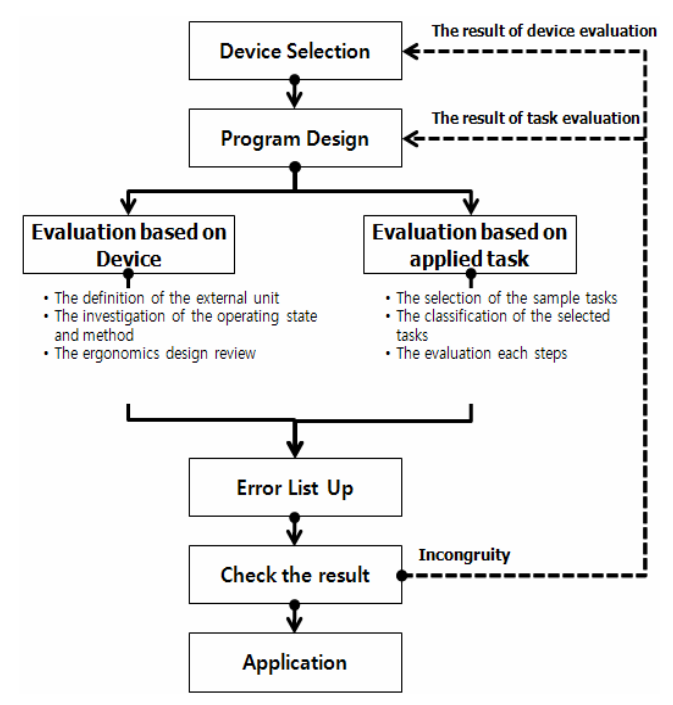

Figure 3. A flowchart of a method for human error potential

\section{Human Error Studies Based on Experimental Measurement}

\subsection{Human error studies by experiment method(based on EEG)}

최근 들어 많은 연구자들이 다양한 이론을 생체신호에 적 용하여 인간의 정보처리 과정에 대한 새로운 현상을 파악 하려는 시도와 노력이 이루어지고 있다. 스포츠 분야에서는 반복적인 학습과 훈련 후 직무 수행도 및 집중도의 효과를 뇌파출현량으로 확인하였고(Jo, 2005) Brain Computer Interface (BCI) 분야에서는 인터페이스를 위한 동작 예 측을 파악하기 위한 이동평균성 Event Related $\mathrm{De}^{-}$ synchronization(ERD), Event Related Synchronization (ERS) 연구가 활발히 진행 중이다(Whang, 2007).

또한 감성 및 인간공학에서는 색채, 조명 등에 대한 인체
반응 연구, 근심과 걱정, 오류와 관련된 brain activity 연구 를 뇌파를 통해 진행하고 있다(Whang, 2008). 자동차 분야 에서는 운전 중 졸림, 멀티 정보처리 과정에서 발생되는 실 수를 파악하기 위한 연구들로 뇌파 연구가 활발히 진행되고 있다. 다양한 분야에서 뇌파를 이용한 인적오류 관련 연구가 진행되고 있으나 원자력 분야에서 인적오류 및 인적오류 가 능성(위험성)과 관련된 뇌파 연구는 극히 일부이다(Lim, 2008, 2010) (Table 2).

Table 2. Researches on EEG related human error

\begin{tabular}{|c|c|c|c|}
\hline No. & Author & Title & Contents \\
\hline 1 & Lim, H.G. & $\begin{array}{l}\text { Variation of relative power } \\
\text { characteristics in EEG while } \\
\text { inducing human errors }\end{array}$ & $\begin{array}{l}\text { - The characteristic investigation } \\
\text { of human error in oddball task } \\
\text { - Variation of relative power } \\
\text { frequency }\end{array}$ \\
\hline 2 & Lim, H.G. & $\begin{array}{l}\text { Influence of time stress on } \\
\text { EEG characteristics related } \\
\text { with human errors }\end{array}$ & $\begin{array}{l}\text { - The characteristic investigation } \\
\text { of human error in arithmetic task } \\
\text { according to time pressure } \\
\text { - Frequency power spectrum } \\
\text { analysis }\end{array}$ \\
\hline 3 & $\begin{array}{l}\text { Gerwin } \\
\text { Schalk }\end{array}$ & $\begin{array}{l}\text { EEG-based communication: } \\
\text { presence of an error } \\
\text { potential }\end{array}$ & $\begin{array}{l}\text { - Mu and beta frequency analysis } \\
\text { - The identification of error } \\
\text { potential }\end{array}$ \\
\hline 4 & $\begin{array}{l}\text { Gethin } \\
\text { Hughes }\end{array}$ & $\begin{array}{l}\text { Dissociable correlates of } \\
\text { response conflict and error } \\
\text { awareness in error related } \\
\text { brain activity }\end{array}$ & $\begin{array}{l}\text { - The comparison between error } \\
\text { related negativity and error } \\
\text { Positivity from flanker task }\end{array}$ \\
\hline 5 & $\begin{array}{l}\text { John R. } \\
\text { Fedota }\end{array}$ & $\begin{array}{l}\text { Neuro-ergonomics and } \\
\text { human error }\end{array}$ & $\begin{array}{l}\text { - The EEG signal analysis in } \\
\text { human error(slip) } \\
\text { - The research on ERN }\end{array}$ \\
\hline 6 & \multicolumn{2}{|c|}{ Human brain map journal } & $\begin{array}{l}\text { - Alpha and mu frequency activity } \\
\text { is increased over } 25 \% \text { before } \\
\text { error }\end{array}$ \\
\hline
\end{tabular}

\subsection{A task design for EEG experiment}

본 연구에서는 원자력 산업에서 적용 가능한 디지털 기기 를 이용하여 주제어실 내 주요 인간공학 현안을 제시한 선행 연구를 기반으로 실험 가능한 실험 직무로 재 설계하였다. 디지털 기기 기반 주제어실 관련 주요 인간공학 현안으로는 컴퓨터 기반 정보표시장치의 interface management tasks 가 있으며 전산화 절차서의 keyhole effect, 소프트제어기의 정보를 slip 발생 가능한 description error, disordering the components of an action sequence, capture error, loss of activation error 등이 있다.

컴퓨터 기반 주제어실 직무 중 계층적 구조형태로 보여주 는 정보는 스크롤을 통해 탐색, 확인해야 하고 정보의 제공 속도 역시 인간의 눈이나 뇌의 처리 속도보다 빨라 운전원 이 처리할 수 있는 양보다 훨씬 많은 정보가 제공될 수 있다. 
전산화 절차서 사용에 따라 운전원간 의사소통이 단절될 수 있고 비상상황 시 운전원 수행도에 문제를 발생시킬 가능성 이 있고 VDU의 제한된 공간으로 keyhole effect가 발생될 수 있다.

소프트제어기의 경우 운전원 행위 부분이 아닌 schema가 동작될 경우 의도치 않은 동작이 발생되거나 사용하는 정보 가 모호하여 운전원의 slip이 발생할 수 있다. 또한 자주 수 행하지 않은 운전을 수행할 때 자주 수행하는 유사한 운전 이 존재할 경우 이를 대신 수행하거나 운전원 메모리의 한 계(decay, interference)로 업무를 수행하지 않는 망각 행 위가 발생 가능하다(Table 3).

Table 3. Ergonomic issues on computer based MCR

\begin{tabular}{|c|c|c|}
\hline Factor & Erg. issues & Hazard factors \\
\hline \multirow{2}{*}{$\begin{array}{l}\text { Information } \\
\text { display based } \\
\text { on computer }\end{array}$} & Information overload & $\begin{array}{l}\text { - Overlapping windows } \\
\text { - Too much information } \\
\text { - Faster information than visual } \\
\text { process of human }\end{array}$ \\
\hline & Interface management tasks & $\begin{array}{l}\text { - Navigation task before the primary } \\
\text { task } \\
\text { - Overworking, Losing the } \\
\text { information because of secondary } \\
\text { task }\end{array}$ \\
\hline \multirow{5}{*}{$\begin{array}{l}\text { Computerized } \\
\text { procedure }\end{array}$} & Team performance & $\begin{array}{l}\text { - Communication dis-connection } \\
\text { between operators }\end{array}$ \\
\hline & Situation awareness & $\begin{array}{l}\text { - The depending on the } \\
\text { computerized procedure }\end{array}$ \\
\hline & Level of automation & - Automation level \\
\hline & Keyhole effect & - The limitation of parallel process \\
\hline & $\begin{array}{l}\text { CPS failure in complex } \\
\text { situation }\end{array}$ & $\begin{array}{l}\text { - The conversion problem of the } \\
\text { paper procedures }\end{array}$ \\
\hline \multirow{6}{*}{$\begin{array}{c}\text { Soft } \\
\text { controller }\end{array}$} & Unintentional activation & - Unintended activity \\
\hline & Description errors & - Slip by ambiguous information \\
\hline & Mode errors & - Mode error \\
\hline & $\begin{array}{l}\text { Disordering the components } \\
\text { of an action sequence }\end{array}$ & $\begin{array}{l}\text { - Skip by the continuous task, } \\
\text { repetition, reverse procedure }\end{array}$ \\
\hline & Capture error & $\begin{array}{l}\text { - Confusion with the task } \\
\text { frequency }\end{array}$ \\
\hline & Loss of activation errors & $\begin{array}{l}\text { - Task Fail because of the limited } \\
\text { memory of operator }\end{array}$ \\
\hline
\end{tabular}

앞서 살펴본 발전소 주제어실에 컴퓨터 기반 직무 대상 인 간공학적 위험성 요인 중 탐색 및 관찰 실패, 직무 누락, 정 보 혼돈, 계층적 정보 기억 실패를 네 가지 대표 오류 가능 성으로 선정하고 이를 기반으로 실험 직무를 다음과 같이 설계하였다.

Task 1은 탐색 및 관찰 실패에 대한 실험 직무로써, 주어 진 문장에서 순서가 뒤바뀐 어휘를 관찰하는 직무이다. Task
2는 연속된 직무를 누락하는 오류를 유발하는 실험 직무로 써, $5 \times 5$ 행렬 내에 연속된 숫자 중 생략된 숫자를 적게는 하나 많게는 세 개를 찾아내는 직무이다. Task 3은 연산 직 무로써 정보 혼돈을 발생시킬 수 있는 음수를 포함한 덧셈, 뺄셈, 곱셈, 나눗셈으로 세 자리에서 다섯 자리 숫자의 연산 조합으로 구성된다. 마지막 task 4 직무에서는 정보 기억 직 무로써 행렬 내 특정 공간의 숫자를 기억하도록 요구하는 직무이다(Figure 4).

\section{TASK 1(30초) \\ 다음 중 순서가 바뀐 어휘 개수는 몇 개입니까? \\ 도덕적 상대주의는 도덕적으로 옳고 그름에 대한 객관적 진리가 존하재지 않는다고 믿는 입장이다. 따라서 어떤 행동이 옳은지 그른지는 각자의 기준에 따라 판단해야 한다고 주장한다. 하지만 세상에 도덕 기준이 존재다한고 해서 도덕적 상대주의가 옳은 입장이라고 할 수는 없다. 이것은 세상에서 일나어는 물리적 현상에 대해서 다양한 이론이 존재하지만, 그렇다고 해서 모든 과학 이론이 뜩같이 옳다고 할 수 없는 것과 마찬가지다.
(1) 2
(2) 3
(3) 4 \\ TASK 2(40초) \\ 다음 배열에서 생략된 숫자는 무엇입니까?

\begin{tabular}{|c|c|c|c|c|}
\hline 1 & 12 & 25 & 4 & 17 \\
\hline 20 & 3 & 11 & 24 & 7 \\
\hline 9 & 15 & 16 & 23 & 19 \\
\hline 18 & 5 & 21 & 14 & 2 \\
\hline 8 & 13 & 22 & 6 & 10 \\
\hline
\end{tabular} \\ (1) 12 (2) 16 (3) 11}

TASK 3(15초)

\section{$2462-75487$}
(1) -73015
(2) -73025
(3) -72025

TASK 4(20초)

다음 배열에서 4행 3열, 7행 4열, 6행 2열에 위치하는 숫자는 무엇입니까?

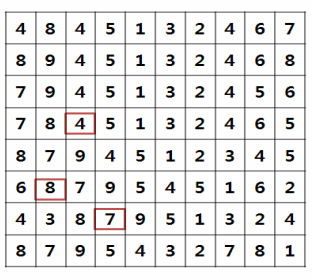

(1) $4,8,7$ (2) $4,7,8$ (3) $4,8,8$

Figure 4. The designed task sample for experiment 


\section{An EEG Analysis for Human Error Identification}

\subsection{Experiment design for EEG}

인적오류는 잘못된 시스템, 인터페이스 설계, 불충분한 훈 련, 부족한 유지보수, 규제정책을 포함하는 다른 요인들의 상호작용으로 발생되기 때문에 실험환경이 극히 제한되고 뇌파 연구가 용이하지 않다. 일부 연구자들은 인간의 실수를 인지적 모형으로 설명함으로써 인적오류의 원인을 파악하고 분류하기도 한다. 본 연구에서는 원자력발전소 운전원들의 인적오류 가능성 (위험성)을 확인하는 실험적 접근 방법으로 뇌파를 활용하고자 한다.

본 실험에서는 뇌파 측정 및 다수의 척도로 데이터 분석을 통하여 디지털 기기 기반 직무에서의 인적오류 가능성 검출 을 목표로 한다. 실험을 위한 기본 가설은 다음과 같다.

- 절대주파수 분석 결과 직무 수행 중 인적오류 검출이 가 능할 것이다.

- 직무 수행 결과(정답/오답, 무응답)에 따라 스펙트럼 값의 차이가 있을 것이다.

- 실험 직무 별 스펙트럼 값의 차이가 있을 것이다.

- 직무 수행 구간 별 스펙트럼 값의 차이가 있을 것 이다.

- 직무 구간 분석 결과 직무 수행 중 인적오류 검출이 가 능할 것이다.

- 직무 수행 동안의 스펙트럼 평균값의 기울기 패턴 분 석 결과 직무 수행 별 차이가 있을 것이다.

- 직무 수행 동안의 스펙트럼 평균값의 증감율 천이 분 석 결과 직무 수행 별 차이가 있을 것이다.

- 각 구간 별 인적오류 검출 확률 값을 도출할 수 있다.

- 뇌파 활성도(mapping) 분석 결과 직무 수행 결과 별, 구간 별 차이가 있을 것이다.

가설 검증을 위해 계획된 실험의 종속변수와 독립변수는 다음과 같다.

- 종속변수: 직무 수행 결과(정답, 오답, 무응답), 실험 직 무 $(\operatorname{task} 1,2,3,4)$, 직무 구간 $(\mathrm{p} 1,2,3,4,5)$

- 독립변수: 베타 $(\beta)$ 파 스펙트럼 값, 기울기 패턴, 증감율 천이, 뇌활성도

실험에 참여한 피실험자는 원자력 관련 직종에 근무하는 남녀 총 20명을 모집하였다. 피실험자는 실험에 앞서 몇 가 지 제한된 실험환경에 적합하도록 수면시간, 카페인 섭취, 음주 및 흡연 등을 제어했다. 실험자는 피실험자에게 충분한
수면시간을 권장하고 카페인, 음주 및 흡연은 자재를 권고 했다.

실험은 실험 장비 및 환경이 구축된 실험실에서 수행되었 으며 온, 습도를 일정하게 유지하였다. 피실험자가 직무 수 행에 대한 스트레스를 받거나 긴장하지 않도록 실험 전 충 분한 교육을 실시하였다.

피실험자는 pilot test를 통해 직무 훈련을 실시하였으며 강화 실험을 위하여 직무 수행 실적에 따라 실험비를 차등 지급하였다.

\subsection{The measurement method and process}

본 연구에서는 원전에서 디지털 기기 기반 직무 수행 시 발생 가능한 인적오류 직무에서의 뇌파 변화를 알아보기 위 해 자발뇌파를 측정하여 알파 $(\alpha)$ 및 베타 $(\beta)$ 파의 frequency spectrum을 분석하였다.

$\mathrm{EEG}$ 는 (주)락싸의 POLYG-I 시스템을 사용하였고 피실 험자의 인구통계학적 데이터는 평균 연령 32.15(4.43)세, 평균 수명시간 8.5(2.0)시간, 평균 카페인 섭취량 1.5(0.5) 잔이며 비 흡연자를 대상으로 실험을 실시하였다. 국제기준 법에 따라 10-20 전극 배치법을 이용하여 전극 부착은 $\mathrm{Fp} 1, \mathrm{Fp} 2, \mathrm{~F} 3, \mathrm{~F} 4, \mathrm{P} 3, \mathrm{P} 4, \mathrm{O} 1, \mathrm{O} 2(8 \mathrm{CH})$ 에 부착하였으 며 모든 전극은 $10 \mathrm{~K} \Omega$ 이하로 측정되었고 생리학적 신호는 band pass filter를 거쳐 초당 $512 \mathrm{~Hz}$ 로 샘플링 하였다. 측정 은 자극 제시 전 안정 상태를 시작으로 반응 후 안정 상태까 지 포함하여 측정하였다. 뇌파 측정 및 분석 절차는 다음과

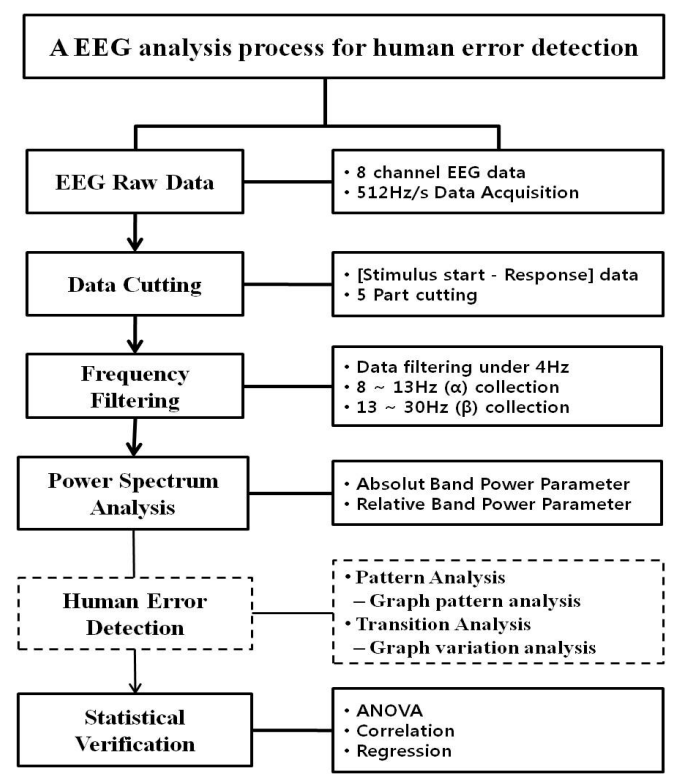

Figure 5. The EEG analysis process 
같다(Figure 5).

피실험자들의 움직임이 최소화되도록 사전에 훈련되었으 며 실험환경을 충분히 제어하였다. 피실험자들은 주어진 직 무를 제한된 시간 내에 완료하도록 하였으며 각 직무 별 20 문항을 수행하고 15 초에서 40 초의 직무 수행시간이 주어졌 다. 또한 각 직무 종료 후 충분한 휴식시간을 제공하여 안정 상태를 유지하도록 하였다. EEG 분석은 정보처리 및 의사결 정 과정에서 사람의 mental 상태를 확인할 수 있는 주요한 방법 중 하나로써 활동적인 육체적, 정신적 활동 수준에서 주로 관찰된다. 특히 베타파 $(13 \sim 30 \mathrm{~Hz})$ 는 시각과 청각 자극 으로부터 불안 상태나 긴장 상태에서 주로 나타남에 따라 인 적오류의 발생 가능성이 높다.

\subsection{The analysis and results}

본 논문에서는 주파수 스펙트럼 분석 후 직무 성공과 실패 시 뇌파의 차이를 분석하고 이후 구간 분석을 통해 구간 내 적분 데이터를 기반으로 그래프의 기울기, 구간 별 증감을 분석하였다.

맵핑(mapping) 데이터를 통해 직무 수행 여부에 따른 뇌 활성도를 직무 수행 처리시간에 따라 확인하였으며 통계적 으로 검증하였다.

$\mathrm{EEG}$ 데이터는 직무를 수행하는 시작(자극 제시)부터 반 응하는 시점까지 총 5 구간으로 나누어 분석되었다(Figure 6). 기존 선행연구에서는 EEG 데이터 분석 특성 상 시간의 흐름에 따라 보는 경우가 거의 없어 직무 수행시간 전체를 분석하였는데 이러한 분석 방법은 직무를 수행하는 동안 사 고 흐름을 파악하기에 제약이 있어서 본 연구에서 기존 분석 방법을 그대로 적용하기에는 문제가 있다. 따라서 본 연구에 서는 별도의 프로그래밍을 통해 수집된 뇌파 데이터를 5 개 의 동일 구간으로 나누어 시간 흐름에 따른 스펙트럼 값의 변화를 살펴보았다.

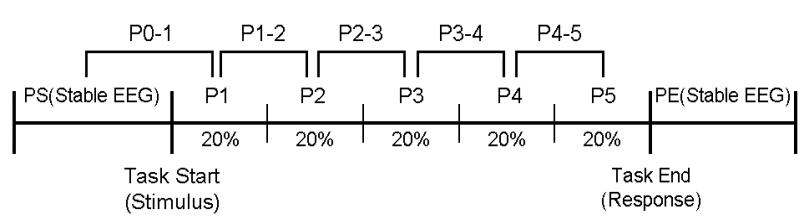

Figure 6. Definitions of the five EEG sections

직무 수행 결과에 따라 직무 수행을 성공시킨 것은 정답 (Correct Answer), 직무 수행 실패 시 잘못된 답은 오답 (Incorrect Answer), 시간 내에 직무 처리 실패한 것을 무 응답(No Answer) 등으로 정의하였다. 인적오류는 무응답과
오답을 모두 포함하여 정답과 비교 분석하였다. 분석은 아래 항목 및 절차로 수행되었다.

$\sqrt{ }$ 절대 주파수 분석 결과(베타파의 파워 스펙트럼 값) 및 상관분석

- 각 직무(T1, T2, T3, T4)에서 직무 수행 결과 $(\mathrm{CA}$,

$\mathrm{IA}, \mathrm{NA})$, 직무 수행 구간(p1, p2, p3, p4, p5) 별 비교 $\sqrt{ }$ 직무 구간 분석

- 직무 수행 구간 그래프 패턴 분석

- 직무 수행 구간 내 증감율 분석(천이)

$\sqrt{ }$ 뇌파 MAPPING 분석: 뇌활성도

1) 절대주파수 분석 결과 및 상관분석

직무 수행 결과에 따라 정답 $(\mathrm{CA})$ 보다 실패(오답; IA 무 응답; NA)에서의 주파수 스펙트럼의 평균값이 높게 나타났 으며 이는 대부분의 직무에서 통계적으로 유의한 차이를 보 였다 ( $p$-value<0.01) (Figure 7) (Table 4).

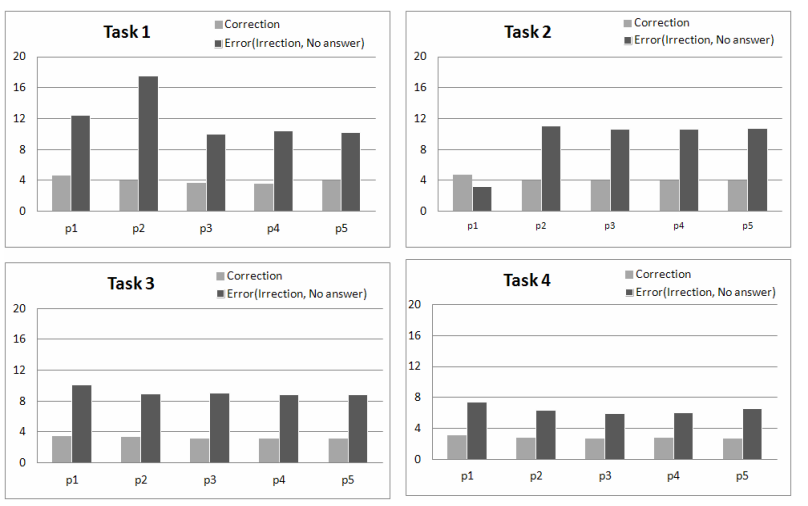

Figure 7. Average of absolute beta power spectrum (correct answer vs. incorrect and no answer)

Table 4. ANOVA analysis(CA vs. Error)

\begin{tabular}{c|c|c|c|c}
\hline Task & Section & $\begin{array}{c}\text { Correct } \\
\text { answer }\end{array}$ & $\begin{array}{c}\text { Error } \\
\text { (IA, NA) }\end{array}$ & $p$-value \\
\hline \multirow{4}{*}{ T1 } & $\mathrm{p} 1$ & $4.66 \pm 3.45$ & $12.42 \pm 8.17$ & $\mathbf{0 . 0 0 1}^{\text {** }}$ \\
\cline { 2 - 5 } & $\mathrm{p} 2$ & $4.00 \pm 2.74$ & $17.51 \pm 33.41$ & 0.129 \\
\cline { 2 - 5 } & $\mathrm{p} 3$ & $3.72 \pm 2.49$ & $9.99 \pm 6.19$ & $\mathbf{0 . 0 0 1}^{\text {** }}$ \\
\cline { 2 - 5 } & $\mathrm{p} 4$ & $3.57 \pm 2.27$ & $10.36 \pm 7.21$ & $\mathbf{0 . 0 0 1}^{\text {** }}$ \\
\cline { 2 - 5 } & $\mathrm{p} 5$ & $4.01 \pm 2.45$ & $10.24 \pm 5.85$ & $\mathbf{0 . 0 0 0}^{\text {** }}$ \\
\hline \multirow{4}{*}{ T2 } & $\mathrm{p} 1$ & $4.68 \pm 12.6$ & $3.243 \pm 8.99$ & $\mathbf{0 . 0 0 2}^{\text {** }}$ \\
\cline { 2 - 5 } & $\mathrm{p} 2$ & $4.01 \pm 2.71$ & $11.00 \pm 7.77$ & $\mathbf{0 . 0 0 2}^{\text {** }}$ \\
\cline { 2 - 5 } & $\mathrm{p} 3$ & $4.03 \pm 2.67$ & $10.58 \pm 6.56$ & $\mathbf{0 . 0 0 1}^{\text {** }}$ \\
\cline { 2 - 5 } & $\mathrm{p} 4$ & $4.03 \pm 2.69$ & $10.63 \pm 6.85$ & $\mathbf{0 . 0 0 1}^{\text {** }}$ \\
\cline { 2 - 5 } & $\mathrm{p} 5$ & $4.01 \pm 2.62$ & $10.74 \pm 6.87$ & $\mathbf{0 . 0 0 1}^{\text {** }}$ \\
\hline
\end{tabular}


Table 4. ANOVA analysis(CA vs. Error) (Continued)

\begin{tabular}{c|c|c|c|c}
\hline Task & Section & $\begin{array}{c}\text { Correct } \\
\text { answer }\end{array}$ & $\begin{array}{c}\text { Error } \\
\text { (IA, NA) }\end{array}$ & $p$-value \\
\hline \multirow{4}{*}{ T3 } & $\mathrm{p} 1$ & $3.48 \pm 1.61$ & $10.11 \pm 4.91$ & $\mathbf{0 . 0 0 0 * *}$ \\
\cline { 2 - 5 } & $\mathrm{p} 2$ & $3.31 \pm 1.49$ & $8.91 \pm 4.19$ & $\mathbf{0 . 0 0 0 * *}$ \\
\cline { 2 - 5 } & $\mathrm{p} 3$ & $3.19 \pm 1.52$ & $8.99 \pm 4.13$ & $\mathbf{0 . 0 0 0 * *}$ \\
\cline { 2 - 5 } & $\mathrm{p} 4$ & $3.18 \pm 1.49$ & $8.83 \pm 4.05$ & $\mathbf{0 . 0 0 0 * *}$ \\
\cline { 2 - 5 } & $\mathrm{p} 5$ & $3.11 \pm 1.40$ & $8.78 \pm 3.49$ & $\mathbf{0 . 0 0 0 * *}$ \\
\hline \multirow{5}{*}{ T4 } & $\mathrm{p} 1$ & $3.12 \pm 1.83$ & $7.35 \pm 4.00$ & $\mathbf{0 . 0 0 1 * *}$ \\
\cline { 2 - 5 } & $\mathrm{p} 2$ & $2.77 \pm 1.43$ & $6.29 \pm 3.41$ & $\mathbf{0 . 0 0 1 * *}$ \\
\cline { 2 - 5 } & $\mathrm{p} 3$ & $2.71 \pm 1.39$ & $5.89 \pm 3.05$ & $\mathbf{0 . 0 0 1} * *$ \\
\cline { 2 - 5 } & $\mathrm{p} 4$ & $2.82 \pm 1.47$ & $6.05 \pm 3.24$ & $\mathbf{0 . 0 0 1} * *$ \\
\cline { 2 - 5 } & $\mathrm{p} 5$ & $2.64 \pm 1.43$ & $6.52 \pm 3.64$ & $\mathbf{0 . 0 0 0 * *}$ \\
\hline
\end{tabular}

4 개 직무 중 $\mathrm{t} 1$ 에서 평균값이 가장 높게 나타났으며 기타 직무에서는 비슷한 결과가 나타났다. 또한 $\mathrm{t} 1$ 에서는 $\mathrm{p} 2$ 구 간에서 주파수 스펙트럼 값이 증가했다가 다시 감소하여 원 래 수준을 유지하는 경향을 보인다. 반면 $\mathrm{t} 2$ 에서는 $\mathrm{p} 2$ 구간 에서 약 3 배 정도 증가한 후 지속되는 것을 확인할 수가 있 었다.

오류 유형 별 절대 파워 스펙트럼 분석 결과 $\mathrm{t} 1$ 의 $\mathrm{p} 2$ 구 간에서 오답의 스펙트럼 값이 10.81에서 19.82으로 약 2배 의 증가 경향이 나타났다.

Task 2, 3, 4에서는 오답과 무응답의 비슷한 경향이 나타 났으며 t3, 4에서는 오답과 무응답의 스펙트럼 값의 차이가 일정 수준으로 유지하는 경향이 나타났다. 또한 $\mathrm{t} 1$ 을 제외하 고는 오답과 무응답이 비슷한 유형을 보이며 무응답이 오답 보다 값이 높게 나타났으나 통계적 유의성은 나타나지 않았 다(Figure 8).

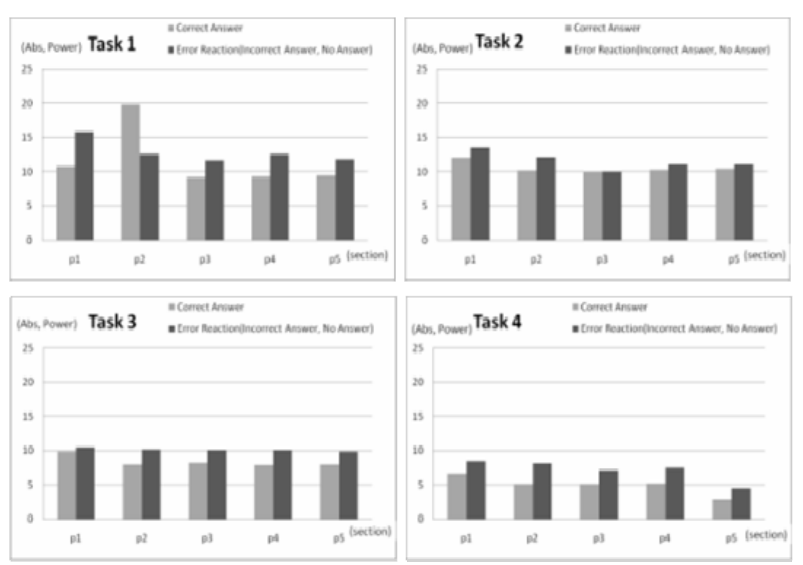

Figure 8. Average of absolute beta power spectrum (Incorrect-Answer vs. No-Answer)
2) 직무 구간 분석

직무 구간 분석은 첫째, 구간 내 기울기 패턴 분석으로 각 구간에서 베타파의 절대 파워 스펙트럼 값에 대한 것을 의미 한다. 정답과 오류(오답, 무응답)간의 기울기가 음의 상관관 계(반대 패턴)로 관찰되면 인적오류 가능성 검출에 중요한 요인이 된다고 해석할 수 있다. 두 번째 방법은 각 구간 내 천이 분석 결과로 각 구간에서 베타파 파워 스펙트럼 변화에 대한 변화량을 의미하며 각 구간의 평균값의 차이를 기반으 로 분석한다.

\section{기울기 패턴 분석 결과}

수행 결과 별 베타파 절대 파워 스펙트럼의 기울기 패턴 분석 결과 $\mathrm{t} 1,3$ 에서는 거의 모든 구간에서 정답과 오류(오 답, 무응답) 간의 매우 유의한 양의 상관관계가 나타났다 ( $p$-value<0.01). 상관계수 또한 $80 \%$ 이상으로 매우 유사 한 기울기 패턴이 나타났다.

$\mathrm{T} 2,4$ 에서는 Table 5 에서 보는 바와 같이 t 2 에서는 $\mathrm{p} 5$ 를 제외한 모든 구간에서 음의 상관관계를 보였으며 $\mathrm{t} 4$ 에서는

Table 5. The correlation coefficient analysis

\begin{tabular}{|c|c|c|c|c|c|}
\hline \multirow{2}{*}{ Task } & \multirow{2}{*}{ Section } & \multicolumn{2}{|c|}{$\begin{array}{l}\text { Correct and } \\
\text { error reaction }\end{array}$} & \multicolumn{2}{|c|}{$\begin{array}{l}\text { Incorrect and } \\
\text { No answer }\end{array}$} \\
\hline & & $\begin{array}{l}\text { Correlation } \\
\text { coefficient }\end{array}$ & $p$-value & $\begin{array}{l}\text { Correlation } \\
\text { coefficient }\end{array}$ & $p$-value \\
\hline \multirow{5}{*}{$\mathrm{T} 1$} & $\mathrm{p} 1$ & 0.966 & $0.000^{* *}$ & 0.591 & 0.162 \\
\hline & p2 & 0.204 & 0.465 & 0.433 & 0.332 \\
\hline & p3 & 0.204 & $0.000^{* *}$ & 0.498 & 0.255 \\
\hline & $\mathrm{p} 4$ & 0.969 & $0.000^{* *}$ & 0.507 & 0.245 \\
\hline & $\mathrm{p} 5$ & 0.953 & $0.000^{* *}$ & 0.590 & 0.163 \\
\hline \multirow{5}{*}{$\mathrm{T} 2$} & $\mathrm{p} 1$ & -0.077 & 0.778 & 0.613 & $0.079^{*}$ \\
\hline & $\mathrm{p} 2$ & -0.169 & 0.531 & 0.602 & $0.087^{*}$ \\
\hline & p3 & -0.109 & 0.689 & 0.539 & 0.135 \\
\hline & $\mathrm{p} 4$ & -0.063 & 0.816 & 0.698 & $0.036^{*}$ \\
\hline & $\mathrm{p} 5$ & 0.034 & 0.900 & 0.738 & $0.023^{*}$ \\
\hline \multirow{5}{*}{$\mathrm{T} 3$} & $\mathrm{p} 1$ & 0.888 & $0.000^{* *}$ & -0.046 & 0.892 \\
\hline & $\mathrm{p} 2$ & 0.791 & $0.000^{* *}$ & -0.151 & 0.658 \\
\hline & p3 & 0.949 & $0.000^{* *}$ & -0.213 & 0.530 \\
\hline & $\mathrm{p} 4$ & 0.884 & $0.000^{* *}$ & -0.168 & 0.621 \\
\hline & $\mathrm{p} 5$ & 0.825 & $0.000^{* *}$ & 0.001 & 0.997 \\
\hline \multirow{5}{*}{$\mathrm{T} 4$} & $\mathrm{p} 1$ & -0.115 & 0.682 & 0.145 & 0.732 \\
\hline & $\mathrm{p} 2$ & 0.110 & 0.697 & 0.049 & 0.909 \\
\hline & p3 & -0.145 & 0.605 & 0.186 & 0.660 \\
\hline & $\mathrm{p} 4$ & -0.238 & 0.392 & 0.252 & 0.546 \\
\hline & $\mathrm{p} 5$ & -0.201 & 0.474 & 0.152 & 0.720 \\
\hline
\end{tabular}


$\mathrm{p} 2$ 를 제외한 구간에서 음의 상관관계를 보였으나 통계적 유 의성은 나타나지 않았다. 오류 간(오답 vs. 무응답) 비교에 서는 스펙트럼 분석의 결과와 유사한 결과로 오답과 무응답 간 차이는 두드러지지 않았으나 $\mathrm{t} 3$ 의 대부분의 구간에서 음 의 상관관계를 보였다(Table 5).

아래 Figure 9은 분석 사례로 정상 직무를 수행한 경우 (실선)와 오류가 발생된 직무(점선) 분석 결과, 4 구간에서 5 구간으로 넘어가는 시점에서 교차하는 패턴이 발생함을 확 인할 수 있다.

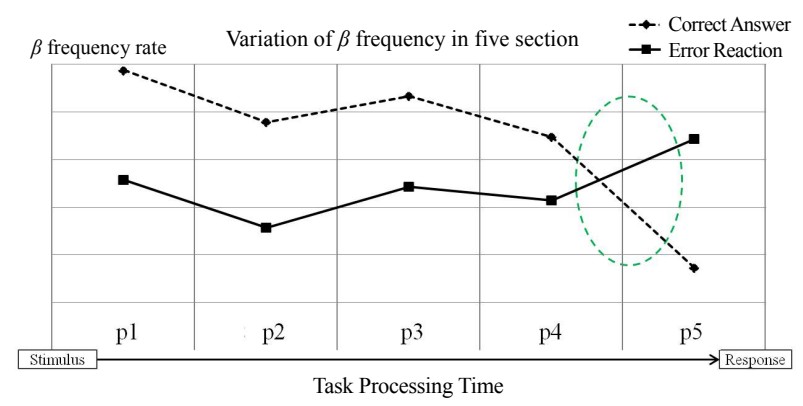

Figure 9. An analysis sample graph

\section{구간 내 천이 분석 결과}

Figure 6에서 정의된 다섯 구간을 데이터 분석을 위해 구 간을 재 정의한다. 직무 수행 전 안정 상태에서 측정한 뇌파 (p0) 와 직무 수행 중에 측정한 첫 번째 구간 $(\mathrm{p} 1)$ 의 천이 값 으로 $\mathrm{p} 0-1$, 다음 구간으로 $\mathrm{p} 1-2, \mathrm{p} 2-3, \mathrm{p} 3-4, \mathrm{p} 4-5$ 로 정의하여 각각 구간의 변화량을 데이터로 활용, 분석하였다.

수행 결과 별 베타파 절대 파워 스펙트럼의 천이 분석 결 과, 공통적으로 모든 직무에서 첫 번째 구간의 천이 값이 약 $70 \%$ 이상으로 다른 구간 천이보다 높은 값이 나타나는데, 이것은 안정뇌파상태에서 자극 제시 후 뇌파 값이 가장 높게 증가한 것으로 판단된다.

각 직무 별 분석 결과로는 $\mathrm{t} 1$ 에서는 $\mathrm{p} 0-1, \mathrm{p} 1-2, \mathrm{p} 4-5$ 구간에서 정답이 오류(오답, 무응답)에 비해 높은 천이 값을 나타났지만, 통계적 유의성은 나타나지 않았다. T2에서는 $\mathrm{p} 0-1$ 구간을 제외한 모든 구간에서 오류가 정답에 비해 높 은 천이 값을 나타냈으며, $\mathrm{p} 3-4$ 구간에서는 $p$-value<0.01 이하의 매우 유의한 차이가 관찰되었다. T4 역시 거의 모든 구간에서 오류의 천이 값이 높게 나타났으며 통계적으로 유 의한 차이를 보였다(Figure 10).

오류 유형별(오답과 무응답) 분석에서는 공통적으로 $\mathrm{p} 0-1$ 구간에서 천이 값이 $50 \%$ 이상으로 가장 높게 나타났으며, 직무에 따라 task 1 과 2에서는 무응답이 오답보다 높은 값 을 보였으며, task 3 와 4 는 오답이 무응답보다 높은 값을 보였다. 그러나 이들 간의 통계적 유의성은 나타나지 않았다.
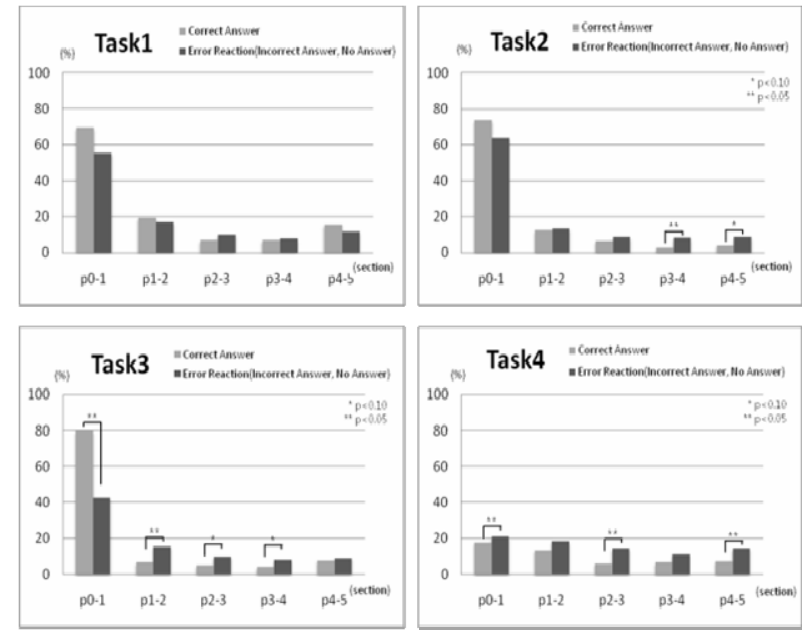

Figure 10. The variation value of the frequency according to the performance results

뇌파의 패턴 크기 분석 결과 각 구간 중 첫 번째 천이 구 간이 인적오류 가능성 검출에 가장 연관성이 높은 구간으로 판단되며, 인적오류 검출을 위한 회귀 분석에서는 첫 번째 천이 구간을 독립변수로 선정하여 그 관계를 분석하였다. 분 석 결과, 정답과 오류 간에서는 모든 직무에서 유의한 차이 를 가지지만 결정계수 $\mathrm{R}^{2}$ 값이 $50 \%$ 미만을 보임으로써 첫 번째 천이 구간만으로는 인적오류 가능성 검출 확률이 $50 \%$ 미만인 것으로 확인할 수 있다. 오류 유형 별 차이는 없는 것으로 확인하였다.

Table 6에서는 앞서 수행된 회귀 분석을 기반으로 구간 별 인적오류 검출 확률을 도출하였다. 구간 별 유의수준 $95 \%$ 에서 유의한 차를 확인할 수 있었으나 상관계수가 높지 않았 다. 연산 직무(t3)에서 가장 높은 오류가 발생한 것과 동일 하게 검출 확률이 약 $48 \%$ 로 첫 구간에서 확인할 수 있었으 며, $\mathrm{t} 2$ 를 제외한 모든 직무에서 유사한 결과를 보였다.

Table 6. The detection probability of each section in tasks

\begin{tabular}{c|r|r|r|r|r}
\hline Prob.(\%) & P0-1 & P1-2 & P2-3 & P3-4 & P4-5 \\
\hline T1 & $\mathbf{2 2 . 9}$ & 2.0 & 1.4 & 0.2 & 2.6 \\
\hline T2 & 12.4 & 0.3 & 1.7 & $\mathbf{2 0 . 3}$ & 8.9 \\
\hline T3 & $\mathbf{4 8 . 0}$ & 14.2 & 8.3 & 6.9 & 0.5 \\
\hline T4 & $\mathbf{1 8 . 3}$ & 4.3 & 21.7 & 3.8 & 11.6 \\
\hline
\end{tabular}

3) 뇌파 맵핑 분석 결과

베타파 주파수 스펙트럼 분석 후 직무 시작부터 반응까지 의 직무 처리 시간 흐름에 따른 맵핑 결과는 Table 7 과 같 
다. 맵핑은 직무를 수행하는 동안 피실험자들의 뇌활성도를 파악하는 것으로 베타파 주파수의 뇌활성도가 정답인 경우 와 오류가 발생된 것과 차이가 있다는 것을 확인할 수 있다. 정답에서는 베타파의 활성도가 p2와 p3에서 가장 높게 나타 났으며 오류가 발생된 직무에서는 직무 시작보다 반응에 가 까울수록 뇌활성도가 높게 나타났다. 이는 직무를 완료해야 하는 시간 압박 및 피실험자의 업무 수행 실패가 직접적인 요인이 된다는 것으로 판단된다.

오른쪽 전두엽에서 뇌활성도가 직무 시간 이후 오답에서 가장 두드러지게 높아 보이며 p5 구간에서 가장 넓은 분포 를 보인다. 무응답에서의 활성도 수준은 오답과 비슷한 양상 을 보인다. 단, 정답에서는 활성도가 높아지다가 $\mathrm{p} 4$ 이후 감 소되는 것을 확인할 수 있다.

Table 7. Brain mapping activities by power spectrum

\begin{tabular}{|c|c|c|c|c|c|}
\hline $\begin{array}{l}\text { Performance } \\
\text { result }\end{array}$ & $\mathrm{P} 1$ & $\mathrm{P} 2$ & P3 & P4 & P5 \\
\hline $\begin{array}{l}\text { Correct } \\
\text { answer }\end{array}$ & & & & & \\
\hline $\begin{array}{c}\text { Error } \\
\text { (incorrect) }\end{array}$ & & & & & \\
\hline $\begin{array}{c}\text { Error } \\
\text { (No-answer) }\end{array}$ & & & & & \\
\hline
\end{tabular}

\section{Conclusion and Discussion}

본 논문에서는 원자력발전소에서 디지털 기기의 활용에 앞서 안전성을 확인하고 인적오류를 검출하기 위한 방법으 로 $\mathrm{EEG}$ 기반한 실험적 방법을 활용하였다. 디지털 기기 사 용에 따른 사용자 반응 특성을 측정하기 위해서는 다양한 생리학적 실험 방법을 활용할 수 있으나 인간의 인지적 오류 에 기반한 인적오류를 검출하였다. 뇌파 데이터 중 인적오류 를 확인 및 검출을 위하여 총 세 가지 접근 방법(주파수 파 워 스펙트럼 분석, 직무 수행 구간 분석, 맵핑)으로 분석했다.

첫째, 주파수 스펙트럼 분석 결과, 상대/절대 주파수 중 절 대 베타파의 주파수 파워 스펙트럼 결과에서 유의한 결과값 을 확인할 수 있었다. 직무 수행 결과 정답인 경우와 오류 (오답과 무응답)인 경우 피실험자들의 뇌파 변화 양상이 두 드러지게 다른 경향이 보임을 확인할 수 있었다. 또한 두 가
지 오류 유형(오답과 무응답) 분석 결과 무응답에서의 주파 수 스펙트럼 값이 높게 나타났는데 이는 시간 압박에 따른 실험 설계 상 직무 종료시간이 다가올수록 긴장이 높아지기 때문으로 판단된다. 또한 피실험자가 오답을 스스로 인식하 는 것보다 무응답이 우선적인 것으로 발생된 결과라 할 수 있다.

둘째, 구간 분석 결과는 본 논문에서 정의한 5 개 구간에서 의 데이터를 그래프로 분석하여 기울기의 패턴을 분석하였 다. 정답과 오류 그래프에서 실험 직무 중 $\mathrm{t} 2, \mathrm{t} 4$ 직무에서 대부분의 구간이 반대 즉 음의 상관관계를 확인할 수 있었다. 이는 직무를 올바르게 수행한 것과 비교하여 오류를 범한 직 무에서의 독특한 뇌파 변화를 확인할 수 있었다. $90 \%$ 이상 의 유의수준에서의 유의한 차가 나타나지 않지만 최소 $20 \%$ 에서 최대 $70 \%$ 유의수준에서 차이가 나타남을 확인할 수 있다.

구간 분석에서는 그래프 패턴 분석 이외에 증감율 천이를 비교하였으며 회귀 분석을 통해 각 직무 구간 별 인적오류 검출율을 추정할 수 있었다. 구간 별 $95 \%$ 의 유의수준에서 유의한 차가 나타났으나 검출 확률은 구간마다 차이가 있으 며 적게는 $3 \%$ 에서 최대 $48 \%$ 정도의 검출 확률로 인적오류 가능성을 포착할 수 있음을 확인하였다.

뇌활성도를 확인하는 맵핑 결과에서는 정성적인 결과로써 직무가 수행되는 시작 시점부터 끝날 때까지 일정 시간 간격 데이터를 도출했다. 정상 직무를 수행한 것과 오류에서 오른 쪽 뇌활성도에서 확연한 차이를 확인할 수 있었다. 이는 직 무를 수행하는 동안 지속적인 추적, 관찰을 통해 좀 더 객관 적인 데이터로 확보해야 할 것이다.

원자력 산업과 같은 대형 체계의 고신뢰도 산업에서의 인 적오류 분석 방법 중 정성적 실험 접근 방법의 중요성이 다 시 부각되고 있으나 검출 방법론의 가능성에 대한 논의가 계 속되고 있다(Fedota and Parasuraman, 2010). 그러나 본 연구에서는 2010년도부터 선행연구를 통해 디지털 기기 사 용에 따른 새로운 인적오류 유형의 사용자 반응에 대한 연구 를 지속하고 있으며 다양한 뇌파 분석 방법 중 인적오류 검 출 가능한 방법을 확인하고 확률적 데이터를 제시하였다. 이 는 추후 원전 디지털화의 안정성 평가 및 인간공학적 설계 검증 확인을 위한 절차 및 방법 연구의 기초 자료로 활용 가 능할 것으로 기대한다.

\section{Acknowledgements}

This research was supported by the nuclear energy research and development project(Grant. 2012M2A8A-4004256) funded by 
the Ministry of Education, Science and Technology.

\section{References}

Chen, X. and Zhou, Z., Assessment of Human-Machine Interface Design for a Chinese Nuclear Power Plant, Reliability Engineering and System Safety, Vol.87, pp.37-44, 2005.

Cho, D.J. and Shim, J.Y., Comparison of Relative Activity by EEG Regions according to EEG Biofeedback Training for 10weeks, Korea Sport Research, Vol.16, No.2, pp.421-430, 2005.

Fedota, J.R. and Parasuraman, R., Neuroergonomics and Human Error, Theoretical Issue in Ergonomics Science, Vol.11, No.5, pp.402-421, 2010

Gerwin, S. and Jonathan, R.W., EEG-based communication: presence of an error potential, Ckubucak Beyriogtsuikigtm, Vol.111, Issue 12, pp.2138-2144, 2000.

Gethin, H. and Nick, Y., Dissociable correlates of response conflict and error awareness in error related brain activity, Neurophychologia, Vol. 49, Issue 3, pp.405-415, 2011.

Jang, T.I. and Lee, Y.H, A Modification of Human Error Analysis Technique for Designing MMI in MPPs, Journal of Ergonomics Society of Korea, Vol.22, No.1, pp.31-42, 2003

Lee, S.J. and Kim, J.W., Human Error Mode Identification for NPP Main Control Room Operations Using Soft Controls, Journal of Nuclear Science and Technology, Vol.48, No.6, pp.902-910, 2011.

Lee, Y.H. et al., Development of an Extremely Low Frequency Human Error Assessment Technology for Digital Devices and Its Applications to the Nuclear Fields, KAERI/ TR-4575, 2011.

Lee, Y.H., Jang, T.I., Lee, Y., Oh, S.H., Kang, Y.J. and Yun, J.H., Research Activities and Techniques for the Prevention of Human Errors during the Operation of Nuclear Power Plants, Journal of the Ergonomics Society of Korea, Vol.30, No.1, pp.75-86, 2011.

Lee, Y.H., A Scrutinized Analysis Method of the Human Error Potential due to the Introduction of New Digital Devices to Nuclear Power Plants, Proc. HCI conference, USA, 2011.

Lim, H.G., Variation of Relative Power Characteristics in EEG while Inducing Human Errors, The Journal of KOSOS, Vol.23, No.3, pp.65 $-70,2008$.

Lim, H.G., Influence of Work Difficulty Variation on EEG Characteristics Related with Human Errors, The Journal of KOSOS, Vol.25, No.3, pp.123-130, 2010

Oh, Y.J. and Lee, Y.H., A Study on the Operator's Erroneous Responses to the New Human Interface of a Digital Device to be introduced to Nuclear Power Plants, Proc. HCI conference, USA, 2011.
Oh, Y.J. and Lee, Y.H., A Study on EEG Signal and Human Error Potential While using a Digital Device in NPPs, Proc. KNS fall conference, 2011.

O' Hara, J., Plant Modernization Programs, Nuclear Plant Journal, 2004.

Youn, J.H., Development of a Human Error Evaluation Method for Introducing Smart Mobile to Nuclear Power Plants, Proc. ESK fall conference, 2011.

Whang, M.C., Kim, K.T. et al., A Research on EEG Synchronization of Movement Cognition for Brain Computer Interface, Journal of the Ergonomics Society of Korea, Vol.26, No.2, pp.167-171, 2007.

Whang, M.C, Kim Y.J. et al., A Research on Training Effect of EEG according to Repetitive Movement of a Hand, The Korean Journal of the Science of Emotion and Sensibility, Vol.11, No.3, pp.357-364, 2008 .

\section{Author listings}

Yeon Ju Oh: ohyj@kaeri.re.kr

Highest degree: $\mathrm{PhD}$, Department of Industrial Engineering, Dong-Eui University

Position title: Researcher, I\&C and Human Factors Division, Korea Atomic Energy Research Institute (KAERI)

Areas of interest: Human Error, Biomechanics, Cognitive System Engineering

Yong Hee Lee: yhlee@kaeri.re.kr

Highest degree: Ms, Department of Industrial Engineering, Seoul National University

Position title: Section Head, I\&C and Human Factors Division, Korea Atomic Energy Research Institute (KAERI)n

Areas of interest: Human-Machine Interface, Human Error, Cognitive System Engineering

Date Received : 2013-01-15

Date Revised : 2013-01-30

Date Accepted : 2013-01-31 